\title{
Reliability and Validity of the Driver Activity Load Index for Assessing Mental Workload among Drivers in Production Companies
}

\author{
Seyed Abolfazl Zakerian¹, Ghasem Zia², Gabriel Nasl Seraji, Kamal Azam4, Alireza \\ Mortezapour ${ }^{5, *}$
}

${ }^{1}$ Associate Professor, Department of Occupational Health Engineering, School of Public Health, Tehran University of Medical Sciences, Tehran, Iran

${ }^{2}$ MSc in Occupational Health Engineering, Department of Occupational Health Engineering, School of Public Health, Tehran University of Medical Sciences, Tehran, Iran

${ }^{3}$ Professor, Department of Occupational Health Engineering, School of Public Health, Tehran University of Medical Sciences, Tehran, Iran

${ }^{4}$ Associate Professor, Department of Epidemiology and Biostatistics, School of Public Health, Tehran University of Medical Sciences, Tehran, Iran

${ }^{5}$ PhD Candidate of Ergonomics, Department of Ergonomics, School of Public Health, Hamadan University of Medical Sciences, Hamadan, Iran

* Corresponding Author: Alireza Mortezapour, Department of Ergonomics, School of Public Health, Hamadan University of Medical Sciences, Hamadan, Iran. Email: amortezapour258@gmail.com

Received: 23/06/2018 Accepted: 22/09/2018

How to Cite this Article: Zakerian SA, Zia Gh, Nasl Seraji G, Azam K, Mortezapour A. Reliability and Validity of the Driver Activity Load Index for Assessing Mental Workload among Drivers in Production Companies. J Occup Hyg Eng. 2018; 5(2): 65-71. DOI: 10.21859/ johe-5.2.65

\begin{abstract}
Background and Objective: Nowadays, the saliency of workload has become more apparent in ergonomic studies. Workload can cause incident since it is directly related to unsafe situations at work. Therefore, it is important to measure workload in different occupations. This study was conducted to evaluate the validity and reliability of driver activity load index questionnaire for assessing the mental load of drivers.

Materials and Methods: This cross-sectional and descriptive-analytic study was conducted on 100 bus drivers operating in one of the manufacturing companies. The validity of the questionnaire was evaluated by academic and queue experts (lay experts). Additionally the reliability of this index was measured through employing Cronbach's alpha and intra-cluster correlation test on the data obtained from 10 participants. Data were analyzed using SPSS (version 18) software.

Results: The mean age of participants was 50.8 years with the standard deviation of 8.29. Furthermore, the mean of work experience among drivers was 22.18 years. The outcome of the Cronbach's alpha coefficient revealed that the reliability of the questionnaire was higher than 0.7 . Furthermore, intra-cluster correlation coefficient of the questionnaire was estimated higher than 0.7 in all factors affecting the interference factor. The obtained results were indicative of moderate and optimum level of reliability.

Conclusion: According to the results of validity and reliability indices, the driver activity load index questionnaire can be used as a valid and reliable questionnaire in Iran to examine and measure the mental load of drivers.
\end{abstract}

Keywords: Drivers; Driver Activity Load Index Questionnaire; Mental Workload; Validity and Reliability 
dof: $10.21859 /$ johe-5.2.65

بروسى روايى و پايايى يرسشنامه دالى (DALI: Driver Activity Load Index) بلهنظور سنجش بار كار فكرى در ارتباط با راندكان يكى از شر كتهاى توليدى

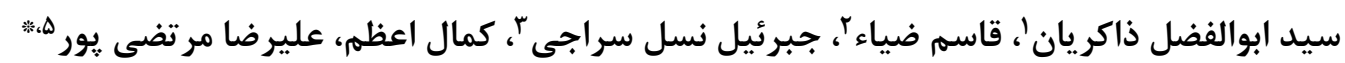

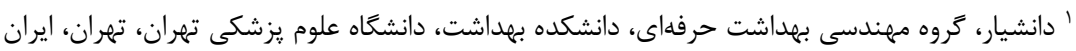

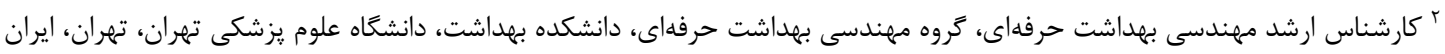

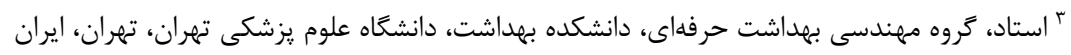

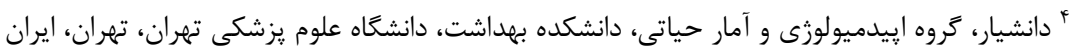

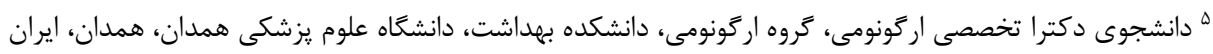
* ن نويسنده مسئول: عليرضا مرتضى يور، كروه اركونومى، دانشكده بهداشت، دانشكاه علوم يزشكى همدان، همدان، ايران ايميل: amortezapour258@gmail.com

جكيده

سابقه و هدف: امروزه در مطالعات اركونومى اهميت باركارى ذهنى بيشتر نمايان شده است. از آنجايى كه

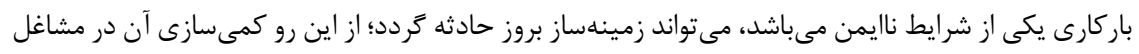

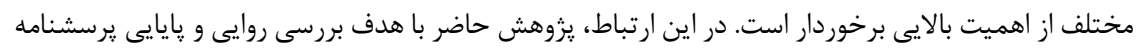
دالى جهت سنجش باركارى ذهنى راندكًان انجام شد.

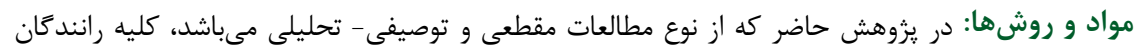

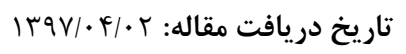

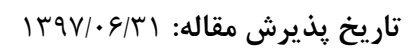
تمامى حقوق نشر براى دانشگاه علوم

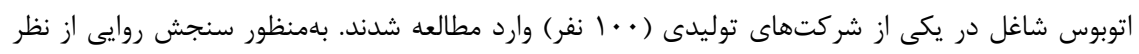

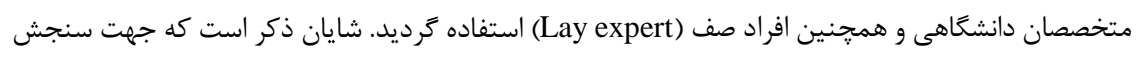

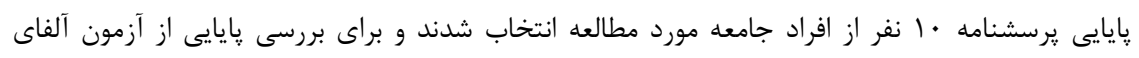

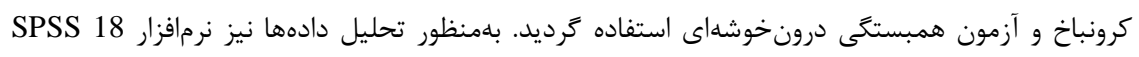
مورد استفاده قرار كرفت.

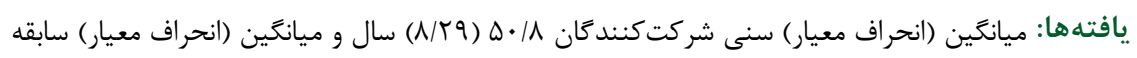

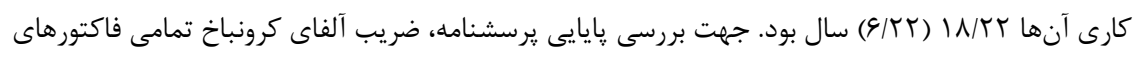

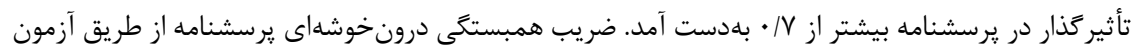

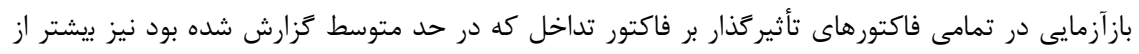

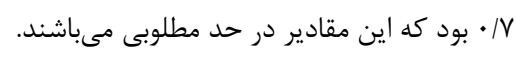

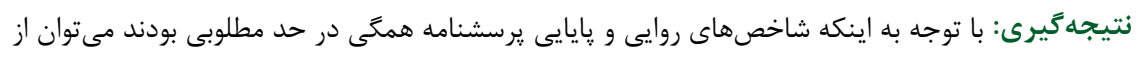

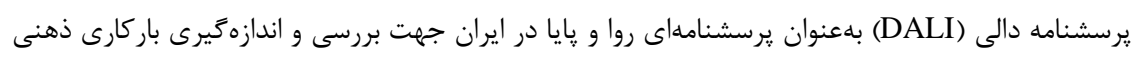
راندكان استفاده نمود.

وازَّان كليدى: باركارى فكرى؛ پرسشنامه دالى؛ راندَّان؛ روايى و پايايى

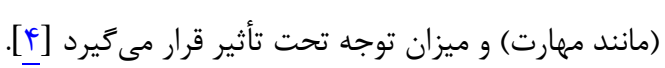

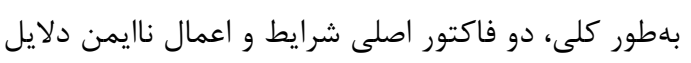
حوادث و صدمات در محيطهاى كارى مى باشند [ـ]ـ. اعمال

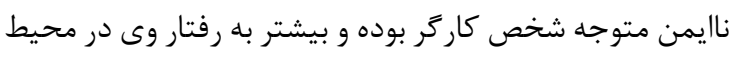

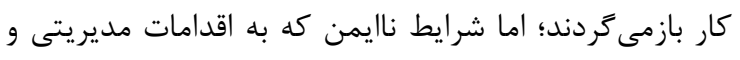

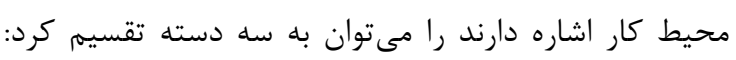

مقلدمه ورود تكنولوزىهاى جديد در محيطهاى كارى، نيازهاى ذهنى بيشترى را نسبت به نيازهاى فيزيكى براى كاركنان اين

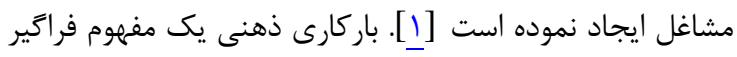

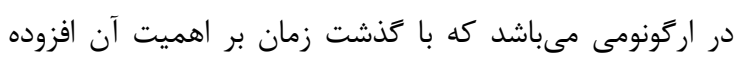

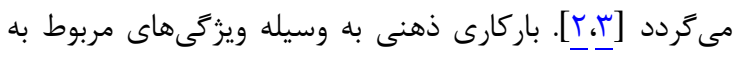

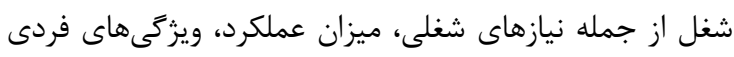


[ [ [1]]. در اين ارتباط، Pauzie و همكار ان در مطالعهاى در مورد

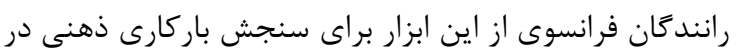

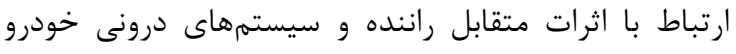

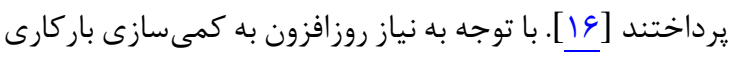

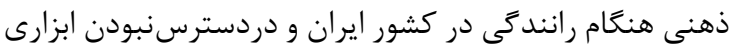

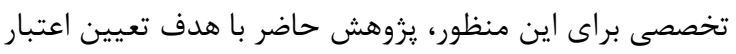

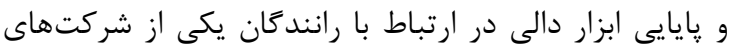

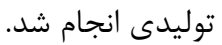

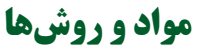

در مطالعه مقطعى حاضر كليه رانندكان اتوبوس كه در يكى إنى

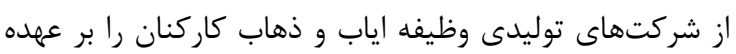

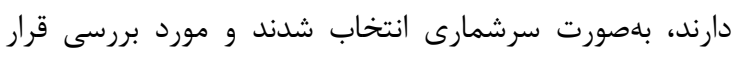

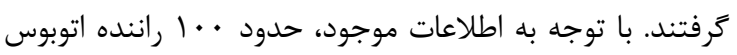
در اين شركت مشغول به فعاليت مى باشند و مطالعه در ارتباط با إنا

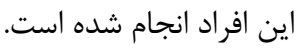

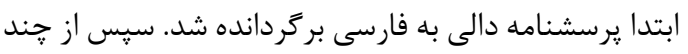

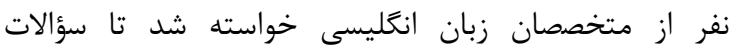

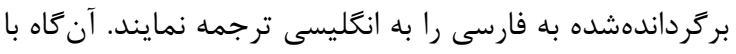

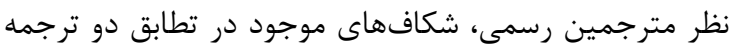

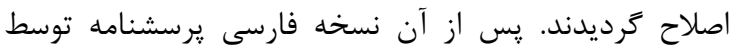

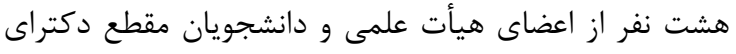

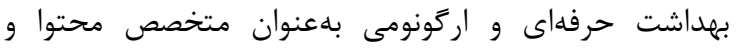

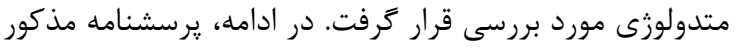

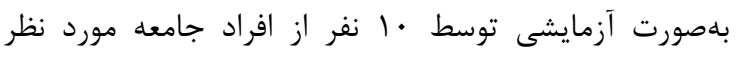

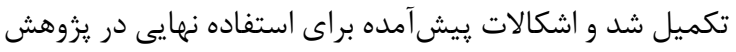

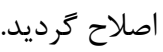
بلمنظور ارزيابى پايايى از طريق آزمون بازآزمايى، • ل انفر به

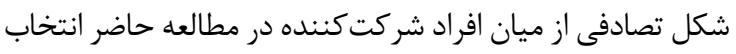

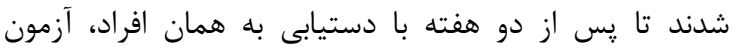
بازآزمايى اجرا كردد.

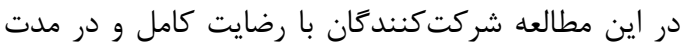

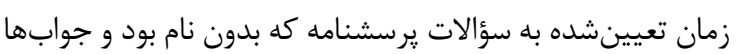

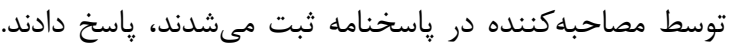

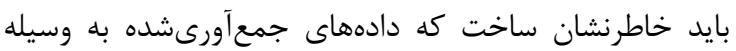

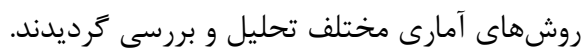
يرسشنامه DALI حاوى سؤالاتى در مورد عوامل تأثير كذار

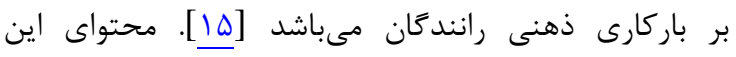

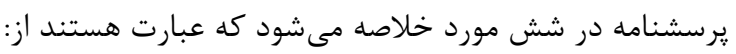

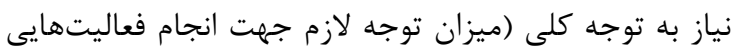

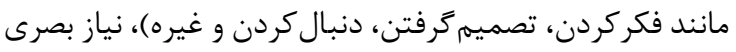

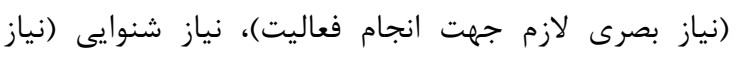

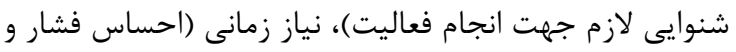

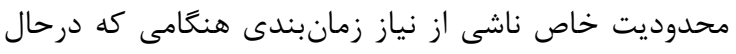

عوامل زيست محيطى، عوامل مديريتى و عوامل ذاتى كار [هـ].

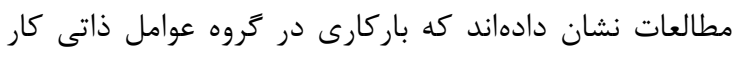

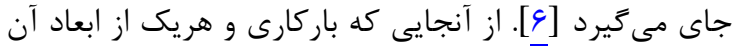

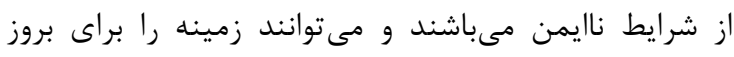

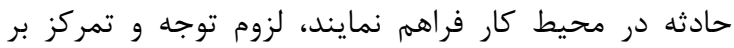

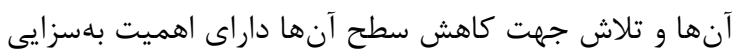

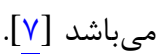

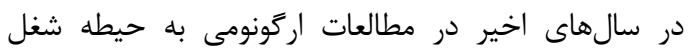

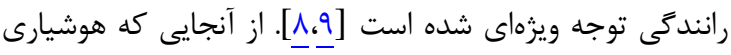

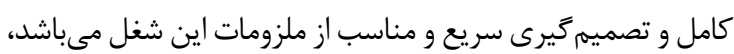

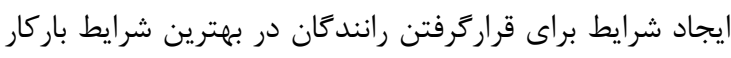

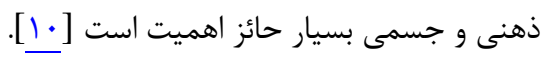

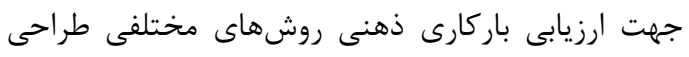

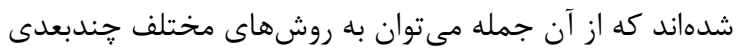
شامل تكنيك ارزيابى باركار ذهنى (SWAT) (Subjective ) NASA-TLX , [11] (Workload Assessment Technique [1] [ و همجنين ابزارهاى (NASA Task Load Index)

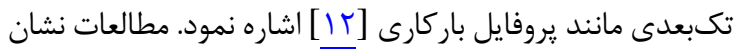

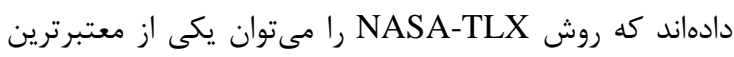

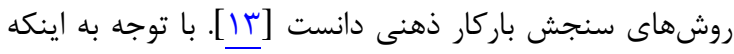

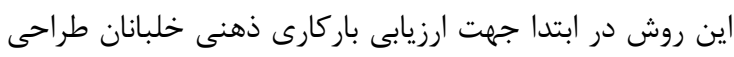

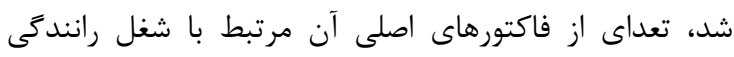

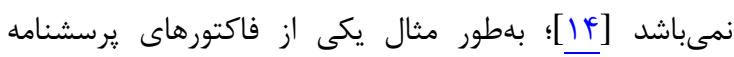

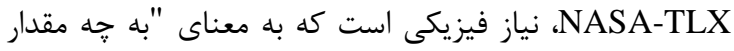

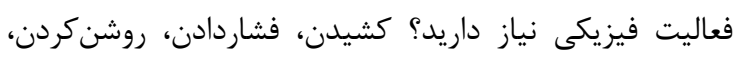

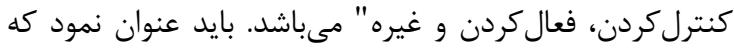

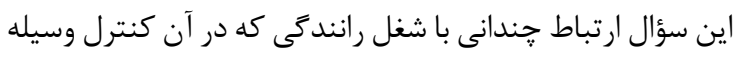

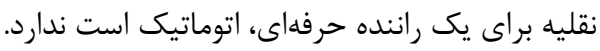

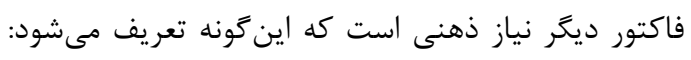

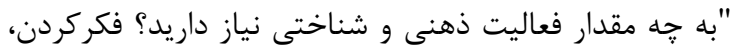

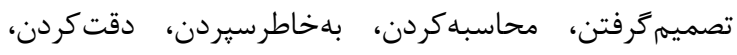

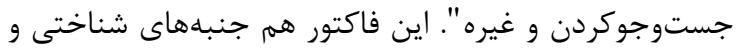

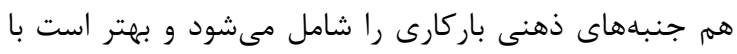

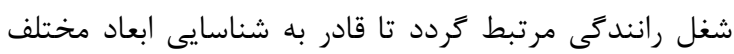
بار كارى ذهنى باشد. از سوى ديكر، بايد به ارزيابى فاكتور "عملكرد" در بارئ

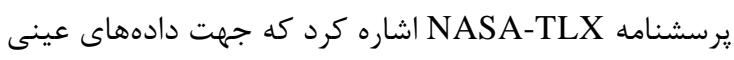

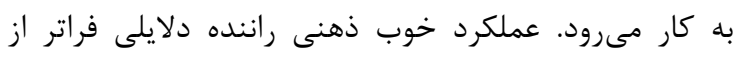

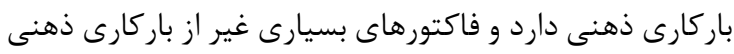

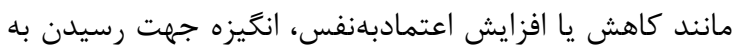

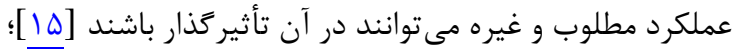
از اين رو با توجه به توضيحات فوق، در مطالعات مختلف از ماز

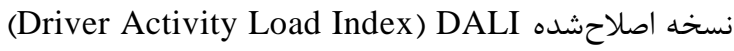
جهت ارزيابى باركارى ذهنى رانندكان استفاده شده است 
شايان ذكر است كه ميانگين و انحراف معيار سن

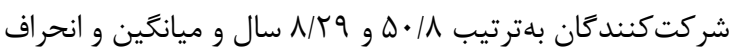

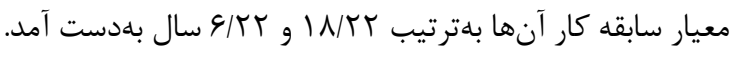

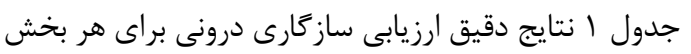

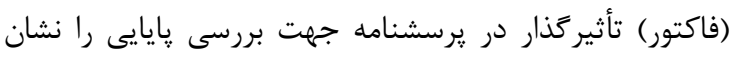
مى دهد. با توجه به جدول فوق، محدوده مقادير فاكتورهاى

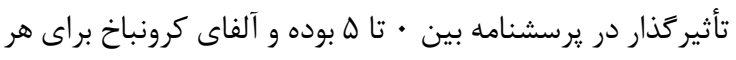

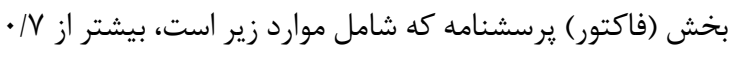
مىباشد: نياز به توجه كلى، نياز ديدارى، نياز شنيدارى، نياز

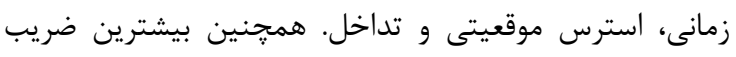

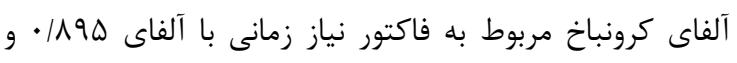

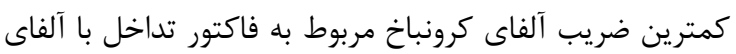

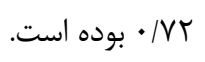

در جدول r تكراريذيرى فاكتورهاى تأثير گذار در يرسشنامه

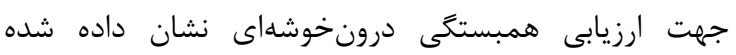

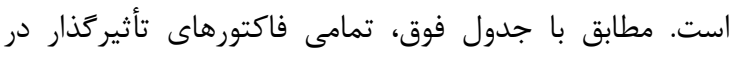

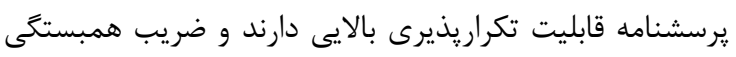

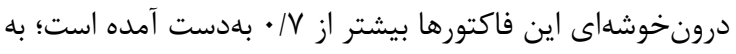

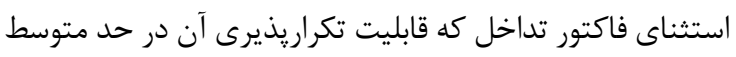

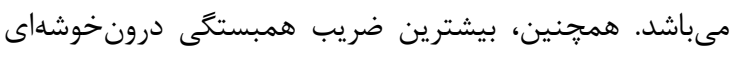

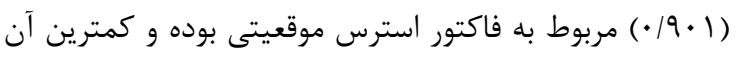
(91V)

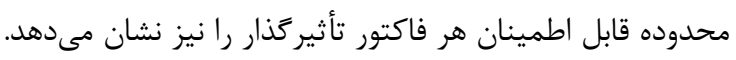
بدينصورت كه بيشترين محدوده قابل اطمينان مربوط به فاكتور

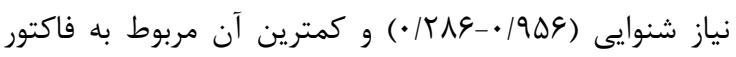

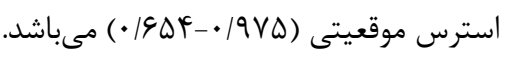

انجام فعاليت هستيد)، تداخل (ارزيابى تداخل هنگامى كه در

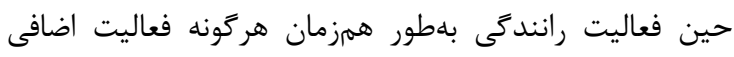
ديخرى مانند استفاده از تلفن، سيستم، راديو و غيره انجام شود) و استرس موقعيتى (سطح استرس در طول فعاليت از قبيل خستتى، احساس نامنى، سوزش، دلسردى و غيره). در اين إنى

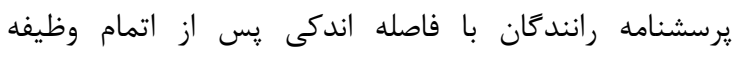

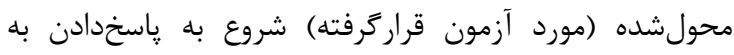

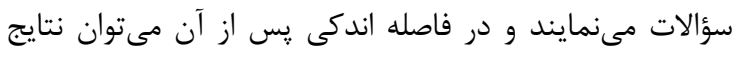
باركارى مختص هر راننده را براى وظيفه انجامشده بهدست آنس آورد.

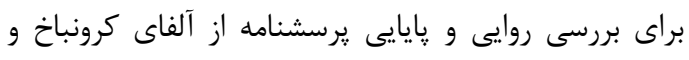

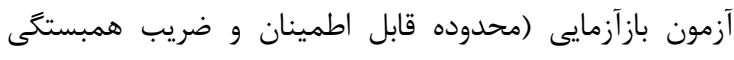

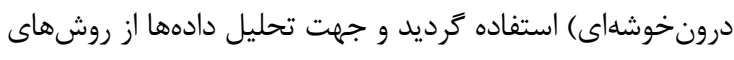

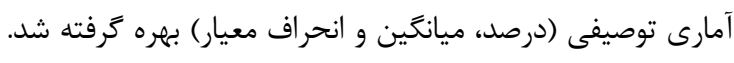

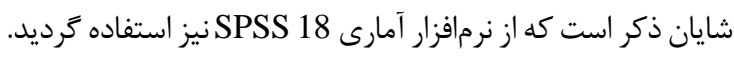

\section{يافتهنا}

نمونه مورد بررسى در يزوهش حاضر متشكل از . ․

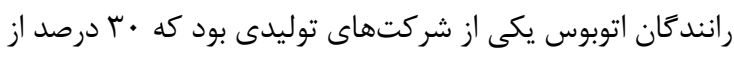

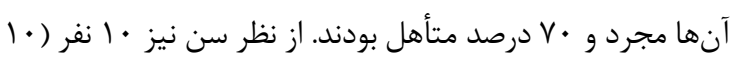

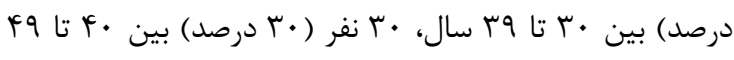

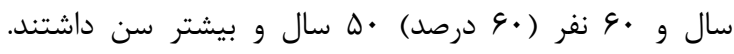

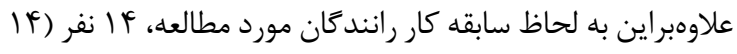

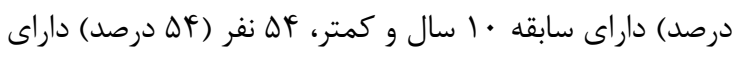

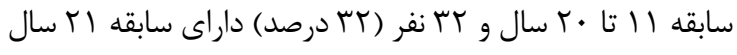

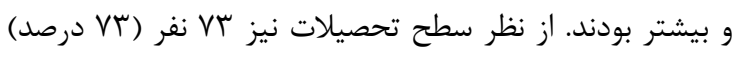
زير دييلم و TV نفر (VV د برصد) داراى مدرك دييلم بودند.

\begin{tabular}{|c|c|c|}
\hline ضريب آلفاى كرونباخ & محدوده مقادير هر فاكتور & فاكتورهاى تأثير كذار \\
\hline ./194 & $\Delta_{-}$ & نياز به توجه كلى \\
\hline$\cdot \mid \Lambda \& V$ & $\Delta_{-} \cdot$ & نياز ديدارى \\
\hline . IATH & $\Delta_{-} \cdot$ & نياز شنوايى \\
\hline$\cdot / 1990$ & $\Delta_{-} \cdot$ & ن ياز زمانى \\
\hline$\cdot|A| \&$ & $\Delta_{-} \cdot$ & استرس موقعيتى \\
\hline.$/ V I T$ & $\Delta_{-} \cdot$ & تداخل ت \\
\hline
\end{tabular}

\begin{tabular}{|c|c|c|}
\hline محدوده قابل اطمينان هף درصد & ضريب همبستكى درون خوشهاى & فاكتور هاى تأثير گذار \\
\hline$\cdot / \cdot-\Delta 9 q / 9 \vee r$ & $\cdot 11 \cdot 9$ & نياز به توجه كلى \\
\hline$\cdot / \cdot-49 \Delta / 99 V$ & $\cdot / V 9 \Delta$ & نياز ديدارى \\
\hline$\cdot / \cdot-r \wedge \& / 9 \Delta \&$ &.$/ V I T$ & نياز شنوايى \\
\hline$\cdot / \cdot-\Delta V G / q V F$ & $\cdot 11 \cdot 9$ & 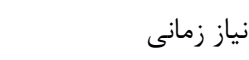 \\
\hline$\cdot / \cdot-9 \Delta F / 9 \vee \Delta$ & $\cdot 19 \cdot 1$ & استرس موقعيتى \\
\hline$\cdot / \cdot-$. TF/VAq & $.191 \mathrm{~V}$ & 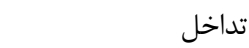 \\
\hline
\end{tabular}


در مشاغل مختلف با توجه به نيازهاى متفاوت آنها مورد

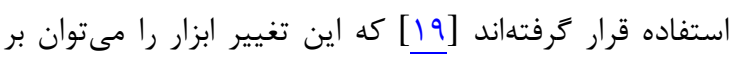

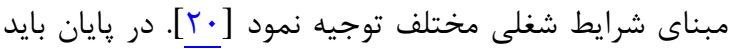

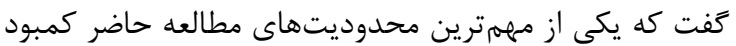

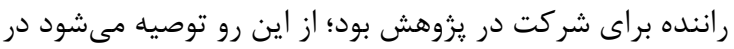

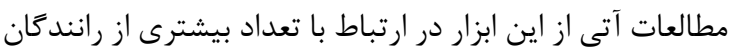
مختلف شهرى و بين شهرى استفاده گردد.

\section{نتيجه كَيرى}

با توجه به نتايج بهدستآمده در ارتباط با بررسى روايى و

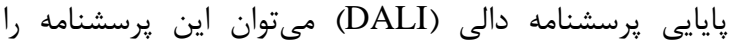

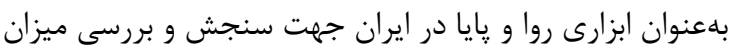
باركارى ذهنى رانندگان مورد استفاده قرار داد. بران

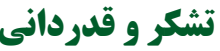

مقاله حاضر بركرفته از يايانامه كارشناسى ارشد رشته

مهندسى بهداشت حرفهاى مىباشد. بدينوسيله يزوهشكران از

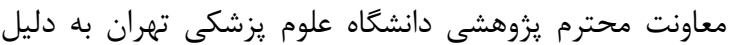
حمايتهاى بىدريغ و نيز از همكارى مديريت حراست و مسئولان

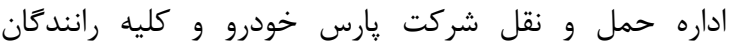
شركت كننده در اين مطالعه تشكر و قدردانى مىنمايند.

\section{REFERENCES}

1. Young MS, Brookhuis KA, Wickens CD, Hancock PA. State of science: mental workload in ergonomics. Ergonomics. 2015;58(1):1-17. PMID: 25442818 DOI: 10.1080/00140139. 2014.956151

2. Parasuraman R, Wilson GF. Putting the brain to work: neuroergonomics past, present, and future. Hum Factors. 2008;50(3):468-74. PMID: 18689055 DOI: 10.1518/ 001872008X288349

3. Longo L. Mental workload in medicine: foundations, applications, open problems, challenges and future perspectives. Computer-Based Medical Systems (CBMS), 2016 IEEE 29th International Symposium on, Dublin, Ireland; 20-24 June 2016. DOI: 10.1109/CBMS.2016.36

4. Bakhshi E, Mazlomi A, Hoseini SM. Mental workload and its determinants among nurses in one hospital in Kermanshah city, Iran. J Occup Hyg Eng. 2017;3(4):53-60. DOI: 10.21859/ johe-03047

5. Shappell SA, Wiegmann DA. A human error approach to accident investigation: the taxonomy of unsafe operations. Int J Aviation Psychol. 1997;7(4):269-91. DOI: 10.1207/ s15327108ijap0704 2

6. Paxion J, Galy E, Berthelon C. Mental workload and driving. Front Psychol. 2014;5:1344. PMID: 25520678 DOI: 10.3389/fpsyg.2014.01344

7. Brookhuis K, van Arem B, van der Horst R, Schaap N. The Relationship between driver distraction and mental workload. Driver distraction and inattention. Florida: CRC Press; 2017. P. 87-104.

8. Matthews G. Towards a transactional ergonomics for driver stress and fatigue. Theoret Issues Ergon Sci. 2002;3(2):195211. DOI: $10.1080 / 14639220210124120$

9. Murphy LA, Huang YH, Robertson MM, Jeffries S, Dainoff MJ. A sociotechnical systems approach to enhance safety climate in the trucking industry: results of an in-depth investigation. Appl Ergon. 2018;66:70-81. PMID: 28958432 DOI: 10.1016/j.apergo.2017.08.002

$$
\begin{aligned}
& \text { نقش و اهميت باركارى ذهنى در زندگى روزمره دليل } \\
& \text { محكمى براى دستيابى به ابزارى مناسب در جهت سنجش و } \\
& \text { ارزيابى اين مسأله مهمم و اساسى است [1]]. يكى از مشاغل مهرم } \\
& \text { و ويزه در مباحث مربوط به باركارى ذهنى، شغل رانندگى } \\
& \text { مىباشد كه به دليل شرايط خاص كارى و كذران بيشتر زمان } \\
& \text { رانندگان در حين رانندگى، در معرض فشارهاى شديد روانى و } \\
& \text { استرسهاى شغلى است كه يكى از عوامل مهلم ايجادكننده آن، }
\end{aligned}
$$

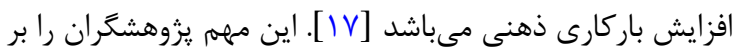

$$
\begin{aligned}
& \text { آن داشته است تا ابزارى تخصصى را براى اين شغل آمادهسازى } \\
& \text { و ارائه نمايند [ع]]. در مطالعات كذشته كه به بررسى روايى و } \\
& \text { ״ايايى يرسشنامه دالى يرداختهاند، نتايج نشان داده است كه در } \\
& \text { نسخه اصلى و انخليسى يرسشنامه DALI، آلفاى كرونباخ بين }
\end{aligned}
$$

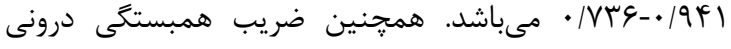

$$
\begin{aligned}
& \text { يرسشنامه كه از طريق آزمون بازآزمايى بهدست مى آيد، بالاتر از }
\end{aligned}
$$

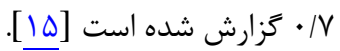

$$
\begin{aligned}
& \text { از سوى ديگر در نسخه اصلى و انگليسى يرسشنامه } \\
& \text { NASA-TLX } \\
& \text { DALI موقعيتى و توجه كلى كه كاملاً مشابه با يرسشنامه } \\
& \text { مىباشد، بيشتر از ᄉ| • بوده و ضريب همبستخى درونخ خوشهاى } \\
& \text { اين سه شاخص بيشتر از ع| • ززارش شده است [11]]. بايد } \\
& \text { خاطرنشان ساخت كه نسخههاى تغييريافته ابزار NASA-TLX }
\end{aligned}
$$

10. Gkikas N. Automotive ergonomics: driver-vehicle interaction. Florida: CRC Press; 2016.

11. Jin L, Cheng LI. Study on the mental workload of high-place operating personnel with the subjective assessment method of swat scale. Saf Environ Eng. 2015;7:3-7.

12. Rizzo L, Dondio P, Delany SJ, Longo L. Modeling mental workload via rule-based expert system: a comparison with NASA-TLX and workload profile. IFIP International Conference on Artificial Intelligence Applications and Innovations, Springer, Cham; 2016.

13. Young MS, Stanton NA. 38 Automotive automation: effects, problems and implications for driver mental workload. Eng Psychol Cognit Ergon. 2017;1:347.

14. Pauzié A. Evaluating driver mental workload using the driving activity load index (DALI). European Conference on Human Interface Design for Intelligent Transport Systems, New York; 2 September 2016. DOI: 10.1007/978-3-31944944-9_19

15. Pauzié A. A method to assess the driver mental workload: The driving activity load index (DALI). IET Intelligent Trans Syst. 2008;2(4):315-22. DOI: 10.1049/iet-its:20080023

16. Rendon-Velez E, Van Leeuwen P, Happee R, Horváth I, Van der Vegte W, De Winter JC. The effects of time pressure on driver performance and physiological activity: a driving simulator study. Transport Res Part F Traffic Psychol Behav. 2016;41:150-69. DOI: 10.1016/j.trf.2016.06.013

17. Pauzié A, Manzano J. Evaluation of driver mental workload facing new in-vehicle information and communication technology. Proceedings of the 20th Enhanced Safety of Vehicles Conference (ESV20), Lyon, France; 2007.

18. Galy E, Paxion J, Berthelon C. Measuring mental workload with the NASA-TLX needs to examine each dimension rather than relying on the global score: an example with driving. Ergonomics. 2018;61(4):517-27. PMID: 28817353 DOI: 10.1080/00140139.2017.1369583

19. Wilson MR, Poolton JM, Malhotra N, Ngo K, Bright E, 
Masters RS. Development and validation of a surgical workload measure: the surgery task load index (SURG-TLX). World J Surg. 2011;35(9):1961-9. PMID: 21597890 DOI: 10.1007/s00268-011-1141-4
20. Hart SG. NASA-task load index (NASA-TLX); 20 years later. Proceedings of the human factors and ergonomics society annual meeting. Los Angeles, CA: Sage Publications Sage CA; 2006. 


\section{يرسشنامه DALI}

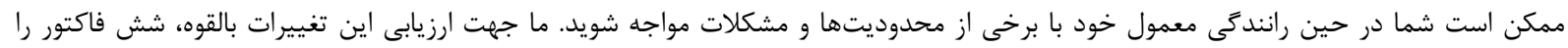

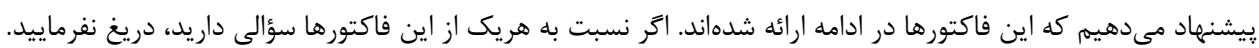

\begin{tabular}{|c|c|}
\hline توضيحات & فاكتور ها \\
\hline نياز ذهنى (انديشيدن / تصميمَرفتن.و غيره)، نياز بصرى و شنيدارى كه براى اتمام كل فعاليت در حين & نياز توجه كلى و يكيارجه \\
\hline نياز بصرى (ديدارى) كه براى اتمام كل فعاليت لازم است. & نياز شنيدارى \\
\hline ميزان يا سطح اضطراب در طول كل آزمون از قبيل خستگى مفرط، احساس تزلزل، رنجش و آزردىى و دلسردى & استرس و اضطراب \\
\hline فشارها و محدوديتهاى خاصى كه در اثر زمانبندى در طول انجام فعاليت ايجاد مىشوند. & نياز زمانى \\
\hline 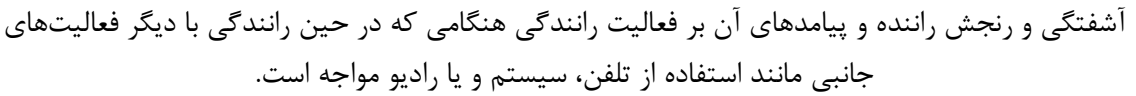 & \\
\hline
\end{tabular}

براى هر فاكتور با توجه به محدوديتى كه در طول رانندگى احساس مى كنيد، مقياسى از • (كم) تا ه (زياد) را انتخاب كنيد. نياز توجه كلى و يكيارجه به جه ميزان توجه كلى در حين فعاليت نياز داريد تا احساسى معمولى در حين رانندگى داشته باشيد؟

\begin{tabular}{|c|c|c|c|c|c|}
\hline بيشترين & & & & & كمترين \\
\hline$\Delta$ & F & $r$ & $r$ & 1 & . \\
\hline
\end{tabular}

به پهه ميزان نياز بصرى در حين فعاليت نياز داريد تا احساسى معمولى در حين رانندگى داشته باشيد؟

\begin{tabular}{|clllll|}
\hline كمترين & & & \\
\hline$\Delta$ & $r$ & $r$ & $r$ & 1 & $\cdot$ \\
\hline
\end{tabular}

نياز شنيدارى

به جه ميزان نياز شنيدارى در حين فعاليت نياز داريد تا احساسى معمولى در حين راندَّى داشته باشيد؟

\begin{tabular}{|c|c|c|c|c|c|}
\hline بيشترين & & & & & كمترين \\
\hline$\Delta$ & $r$ & $r$ & $r$ & 1 & . \\
\hline
\end{tabular}

استرس و اضطراب

به حه ميزان استرس در حين فعاليت نياز داريد تا احساسى معمولى در حين رانندگى داشته باشيد؟

\begin{tabular}{|clllll|}
\hline كمترين & & & \\
\hline S & & & & & \\
\hline
\end{tabular}

نياز زمانى

به جه ميزان فشار مرتبط با زمان جهت انجام كل فعاليت رانندگى نياز داريد تا احساسى معمولى در حين رانندگى داشته باشيد؟

\begin{tabular}{|clllll|}
\hline كمترين & & & \\
\hline$\Delta$ & $r$ & $r$ & $r$ & 1 & $\cdot$ \\
\hline
\end{tabular}

تداخل

به جه ميزان اصلاحات در رفتار رانندگى در حين فعاليت نياز داريد تا احساسى معمولى در حين رانندگى داشته باشيد؟

\begin{tabular}{|clllll|}
\hline كمترين & & & \\
\hline$\Delta$ & $r$ & $r$ & $r$ & 1 & $\cdot$ \\
\hline
\end{tabular}

